\title{
The Arterial System of the Head and Neck of the Rhesus Monkey with Emphasis on the External Carotid System '
}

\author{
WALTER A. CASTELLI ${ }^{2}$ aND DONALD F. HUELKE \\ Department of Anatomy, The University of Michigan, \\ Ann Arbor, Michigan
}

\begin{abstract}
The arterial plan of the head and neck of 64 immature rhesus monkeys (Macaca mulatia) was studied using four techniques - dissection, corrosion preparations, cleared specimens, and angiographs. In general, the arterial plan of this area in the monkey is similar to that of man. However, certain outstanding differ. ences were noted. The origin, course, and distribution of all arteries is described as well as the vascular relations to pertinent structures.
\end{abstract}

As has been mentioned previously (Dyrud, '44; Schwartz and Huelke, '63) the rhesus monkey is useful for many types of medical and dental investigations, yet its detailed gross morphology is virtually unknown. Although certain areas of the monkey have been studied in detail brachial plexus, facial and masticatory musculature, subclavian, axillary and coronary arteries, orbital vasculature, and other structures (Schwartz and Huelke, '63; Chase and DeGaris, '40; DeGaris and Glidden, '38; Chase, '38; Huber, '25; Weinstein and Hedges, '62; Samuel and Warwick, '55; Eyster, '44; Wagenen and Catchpole, '56; Tokarski, '31; Kennard, '41), other areas have been virtually overlooked or have received but passing attention. The literature on the arterial supply of the primate head has been adequately summarized by Dyrud ('44). Very few investigators, however, have used Macaca mulatta specimens and more importantly in most of the articles only brief descriptions have been presented with many of the pertinent morphological details not having been stated, or overlooked. Additionally, only a few specimens have been used in the majority of these works. It is our purpose to present the arterial plan of the head and neck, especially that of the external carotid arterial system.

\section{MATERIALS AND METHODS}

Sixty-four immature rhesus monkeys (Macaca mulatta) were used for this study. All of the animals were embalmed with
$10 \%$ formalin except 17 which were unembalmed. Four different techniques were used for the study of the arterial distribution: (1) dissections -27 specimens; (2) corrosion preparations - 6; (3) cleared specimens - 15; (4) angiographs - 16 heads ( 11 unembalmed and 5 embalmed). The arterial system of the specimens used for dissection was injected with vinyl acetate, red latex, or with a red-colored gelation mass. For the dissection of smaller arteries, the smallest of $150 \mu$ in diameter, the binocular dissection microscope was used. The corrosion specimens were prepared by injecting the arteries with vinyl acetate followed by maceration of the soft tissue with potassium hydroxide (3-10\%) for 24 to 72 hours. The dye selected for injection of the cleared specimens was Teichmann's paste (Teichmann, '52) colored with cinnabar. These specimens were decalcified in $4 \%$ nitric acid and then cleared by the Spalteholtz method. The radiopaque material for the angiographs was the modified Schlessinger's mass (Reiner and Rodriguez, '57), the main components being mercury and barium sulfate.

The head and neck was removed from the animal at the level of the clavicles or, in some cases, a V-shaped section was made with the apex extending down to the arch of the aorta. Both common carotid

1 This investigation was supported (in part) by USPHS research grant DE-00895 from the National Institute of Dental Research, National Institutes of Health, Bethesda, Maryland.

2 Present address: Department of Anatomy, University of Concepcion, Concepcion, Chile. 
arteries, or the left common carotid artery and the brachiocephalic arterial trunk were cannulated depending on the individual situation; paraffin (Castelli, '63) or dental stone was applied to the cut surface to provide adequate vascular resistance so that the injected material would pass through the arterial channels and not seep out through the exposed tissue. Photographs of all stages of dissection were taken, as well as of many of the corrosion and cleared specimens.

\section{OBSERVATIONS}

Common carotid arteries. Minor variations as to the origins of the common carotid arteries were found. Most often a trunk, averaging $7 \mathrm{~mm}$ in length, arises from the apex of the aortic arch and is the origin to the left common carotid artery and the brachiocephalic artery. At times a very short common trunk is found; however, on sectioning the aorta, it is noted that both vessels have independent openings separated only by a thin septum. Of 32 specimens studied, the left common carotid artery and brachiocephalic trunk arose separately from the aortic arch in only one animal (figs. 1 and 2).

The common trunk passes anterior to the left side of the trachea; between the superior vena cava on the right and the left subclavian artery, left vagus nerve, and left phrenic nerve (fig. 2).

The brachiocephalic artery has an oblique upward course across the front of the trachea and averages $16 \mathrm{~mm}$ in length. It is covered by the left brachiocephalic vein, or the superior vena cava, and by adipose tissue of the superior mediastinum. The brachiocephalic artery terminates in the thorax by bifurcating into the right common carotid and right subclavian arteries (fig. 2).

The right common carotid artery has a short intrathoracic course $(8 \mathrm{~mm})$ ascending along the right side of the trachea (fig. 2 ). Close to the apex of the thorax it is covered by the origins of the sternohyoid and sternothyroid muscles.

The left common carotid artery passes directly upward through the thorax medial to and slightly behind the left vagus nerve, adjacent to the left lung. It is covered by the adipose mass of the supe- rior mediastinum and as it leaves the thoracic cavity, it is crossed by the left brachiocephalic vein.

At the base of the neck, the common carotid arteries are less than $1 \mathrm{~cm}$ apart. They diverge from one another through their course in the neck, and, at the level of the carotid bifurcation, they are $3 \mathrm{~cm}$ apart. The common carotid artery is covered by the sternomastoid muscle and lies medial to the internal jugular vein with the vagus nerve behind and between them. At approximately the mid-neck level, the common carotid artery is crossed by the omohyoid muscle, and the artery is tightly bound to the posterior surface of the lateral lobe of the thyroid gland. The common carotid artery divides into the external and internal carotid arteries approximately $1 \mathrm{~cm}$ above the angle of the mandible (fig. 3). The bifurcation of the common carotid artery is 4 to $5 \mathrm{~cm}$ above the level of the sternoclavicular joint.

External carotid artery. At the carotid bifurcation the external carotid artery is anterior and only slightly lateral to the internal carotid artery. The internal carotid artery is tightly applied to the lateral wall of the pharynx by the posterior digastric muscle. The external carotid artery runs parallel to the internal carotid artery for approximately $1 \mathrm{~cm}$, then passes between the stylohyoid and posterior digastric muscles. Above the posterior digastric muscle it swings laterally and passes obliquely upward through the parotid gland toward the posterior border of the ramus of the mandible reaching it slightly beneath the condylar neck. Here the external carotid artery continues forward, medial to the ramus, as the maxillary artery. Sometimes, at this point, a very small superficial temporal artery is given off (fig. 3).

1. The superior thyroid artery is the first branch of the external carotild artery, arising a few millimeters beneath the lingual-facial trunk, or as a branch of this trunk. The superior thyroid artery is found inferior to the hypoglossal nerve and the posterior digastric muscle. The artery is extremely short (approximately $5 \mathrm{~mm}$ in length) and fans out into several branches. One, a superior laryngeal branch, passes horizontally deep to the thyrohyoid muscle 


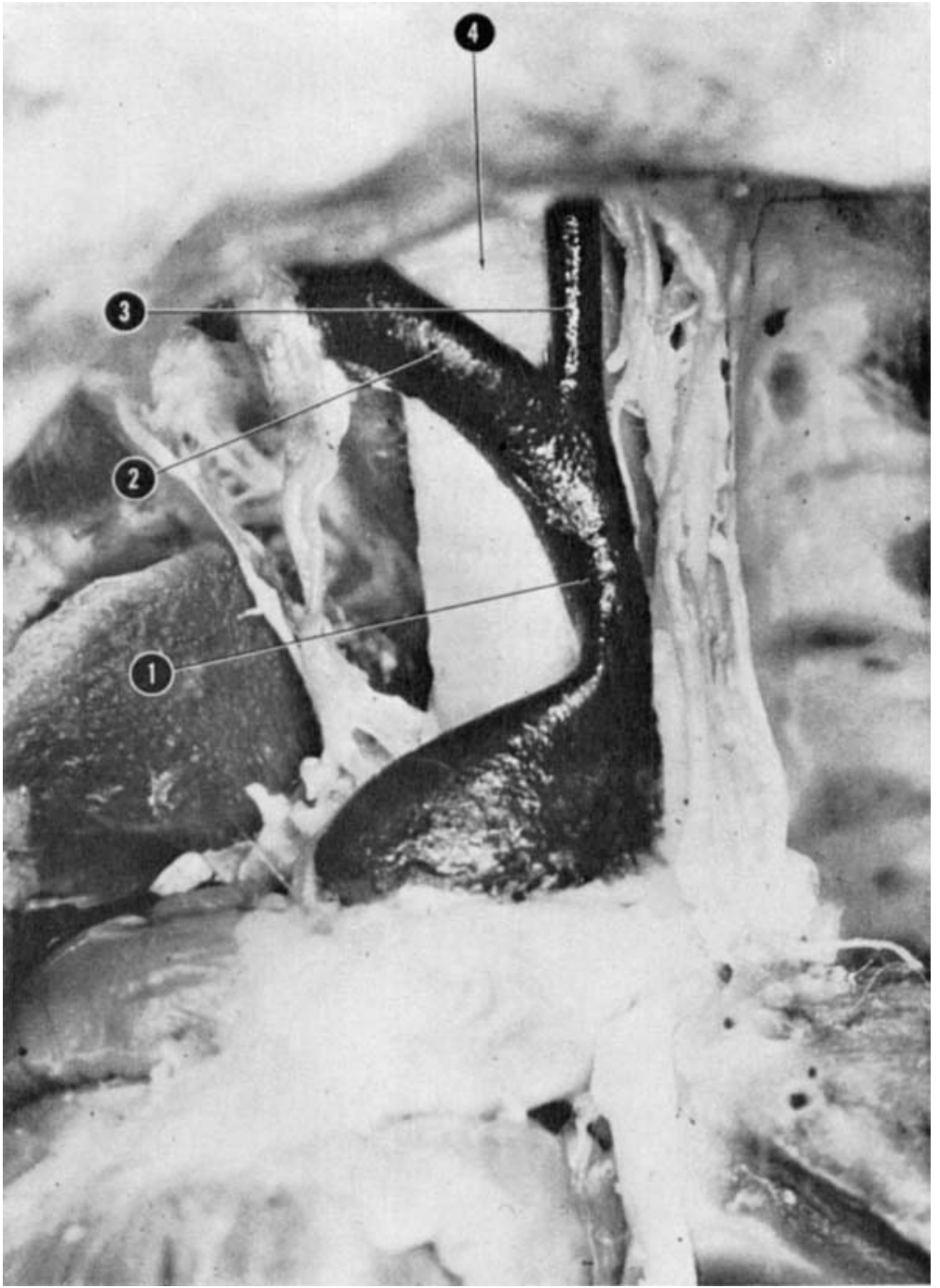

Fig. 1 The common arterial stem (1) of the brachiocephalic trunk (2) and left common carotid artery (3) overlying the trachea (4). (Dissection preparation.)

and perforating the thyrohyoid membrane, supplies the upper part of the larynx. Another branch continues downward to supply other infrahyoid muscles. A terminal branch passes to the medial side of the thyroid lobe, and from it very small branches arise to supply the isthmus of the thyroid gland and the upper part of the trachea. One or two small thyroid terminal branches are given off at the level of the apex of the lateral lobe. One of these passes downward on the lateral border of the lobe; the other, on the posterior aspect of the lateral lobe (fig. 3 ).

2. The lingual-facial trunk arises from the anterior part of the external carotid artery 1 or $2 \mathrm{~mm}$ beyond its origin. The trunk passes forward and slightly upward deep to the posterior digastric muscle; near its origin the hypoglossal nerve is lateral to the trunk and further on the nerve passes deep to the trunk to reach the tongue. The vessel continues forward for a distance of approximately $1 \mathrm{~cm}$ and di- 


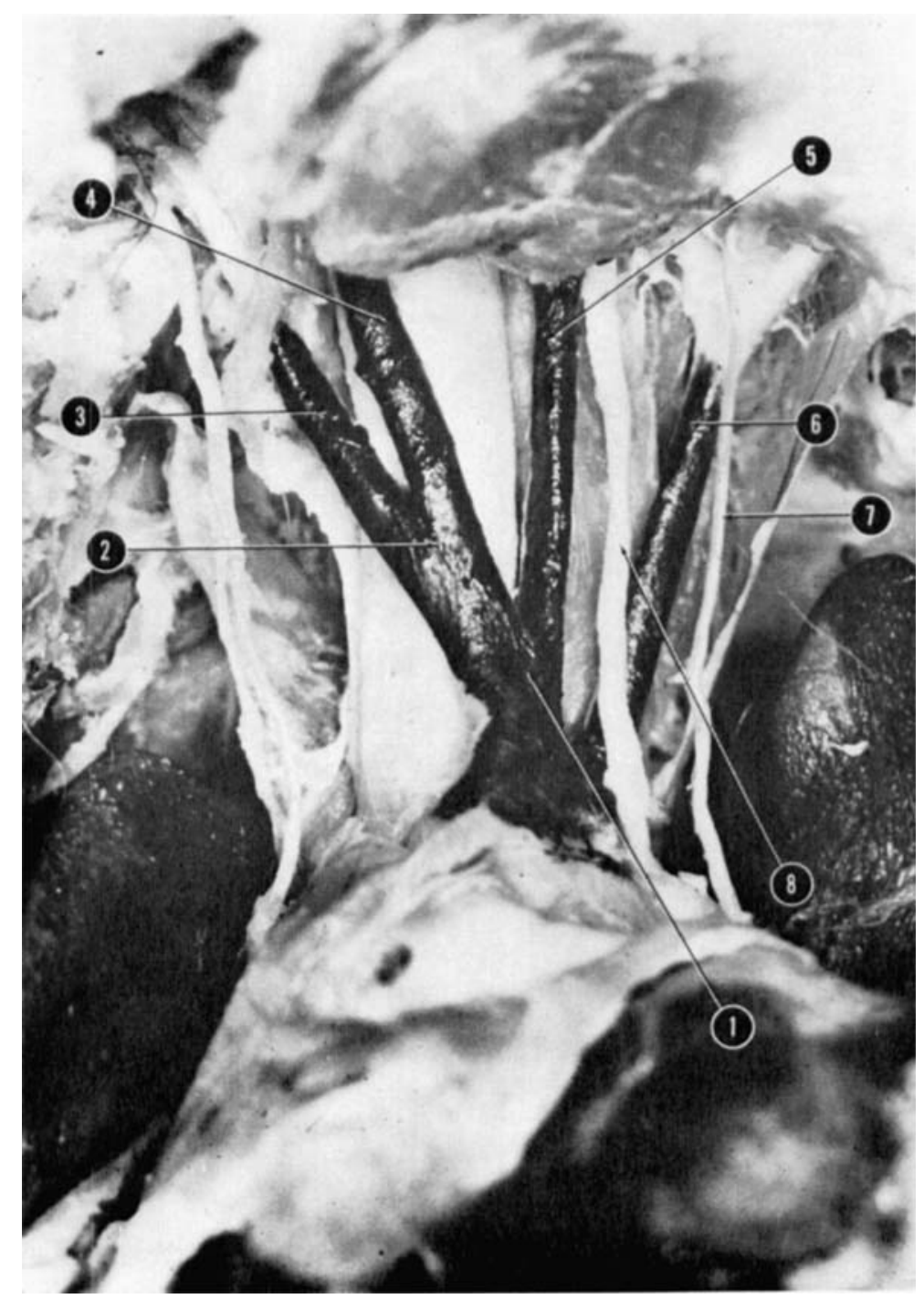

Fig. 2 The large arteries in the upper mediastinum. The common arterial stem (1); brachiocephalic trunk (2); right subclavian artery (3); right common carotid artery (4); left common carotid artery (5); left subclavian atery (6); phrenic nerve (7); vagus nerve (8). (Dissection preparation.)

vides into two main branches, the lingual and facial arteries (figs, 3 and 4 ).

The lingual artery appears to be a direct continuation of the common trunk. It passes deep to the hyoglossus muscle continuing to the tip of the tongue where it terminates. It gives rise to three main branches: dorsal lingual, deep lingual, and sublingual arteries (fig. 4).
The dorsal lingual branches are multiple vessels arising from the lingual stem before it divides into the larger deep and sublingual arteries. The dorsal lingual branches are distributed mainly to the posterior of the tongue, the adjacent lingual mucosa, the glossoepiglotic fold, palatine tonsil, and muscles of the area. Other muscular branches from the lingual artery 


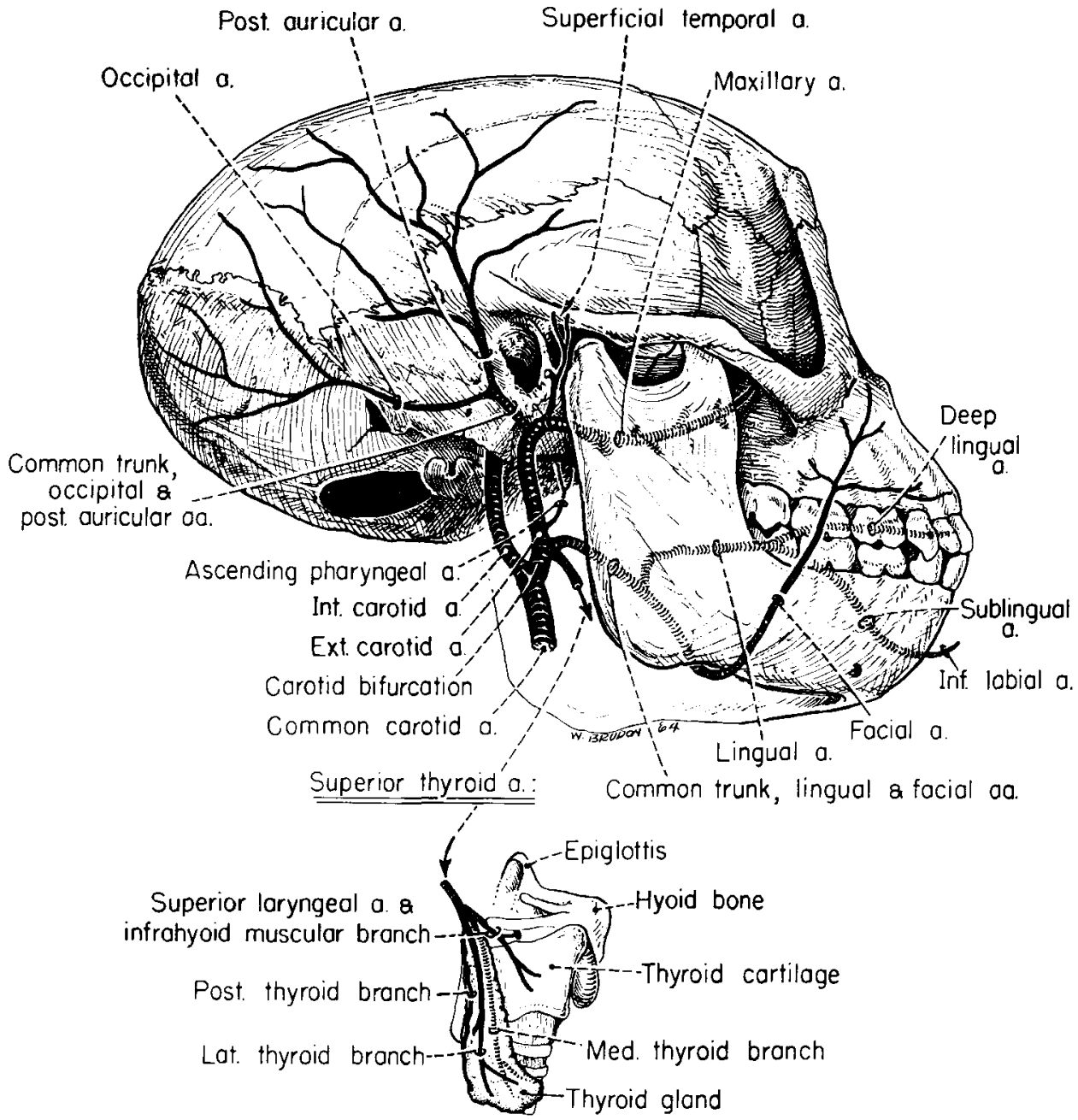

Fig. 3 Schematic drawing showing the course of the main branches of the external carotid artery.

pass downward to supply the hyoglossus and the thyrohyoid muscles (fig. 4).

The deep lingual artery is the principal vessel of the tongue and much of the vascularization of the horizontal portion of the tongue is dependent upon it. Ascending branches arise from it which parallel each other in their course towards the surface of the tongue. Before reaching the tongue mucosa they branch profusely and anastomose with each other to form an arterial network which is apparent throughout the entire dorsal surface of the tongue in the cleared specimens. From this vascular network yet another smaller network is formed by parallel arterioles which branch off toward the submucosa (fig. 4).

The sublingual artery passes towards the symphysis of the mandible in a deeper plane through the tongue; frequently it is double. Numerous branches to the sublingual gland arise from it, the largest of which arises from the lingual artery behind the origin of the main sublingual artery. The sublingual branch as it passes anteriorly is in contact with the lateral aspect of the genioglossus muscle. Throughout its course the artery supplies 


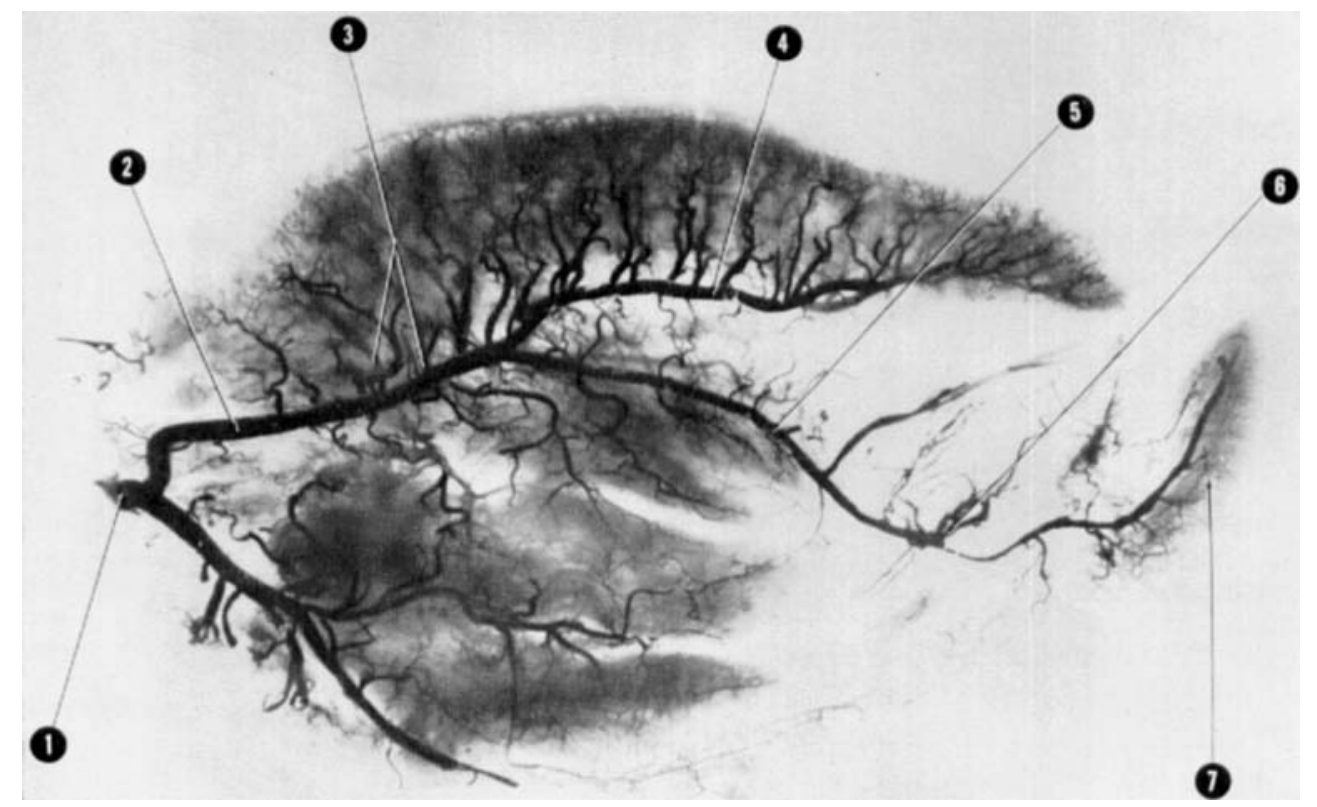

Fig. 4 The distribution of the lingual artery. Lingual-facial trunk (1); lingual artery (2); dorsal lingual branches (3); deep lingual branch (4). Note the sublingual branch (5) passing through the incisive area of the mandible (6) and into the lower lip (7). (Teichmann's paste injection, decalcified and cleared preparation.)

the genioglossus and geniohyoid muscles and it anastomoses with mylohyoid and submental branches of the facial artery. Additionally, it supplies the lingual alveolar mucosa, the attached and free gingiva. At the symphysis, medial to the geniohyoid attachment, and directly on the midline, either the right or left sublingual artery continues through a symphyseal foramen into the lower lip. As the artery passes through the mandible, it supplies branches to the pulp, periodontal membrane, and supporting bone tissue of the central and lateral incisors (fig. 4). In the lip the artery passes vertically upward toward the free border; it bifurcates into right and left branches which distribute to the lower lip, labial mucosa and gingiva. The sublingual branches in the lip anastomose with small branches of the facial artery forming an arterial network around the mouth (fig. 5).

The facial artery passes downward and forward lateral to the hypoglossal nerve and the thyrohyoid muscle. Laterally it is in contact with the lower part of the medial pterygoid muscle. The artery then curves around the inferior border of the mandible where it contacts the upper part of the submandibular gland. It passes onto the face in front of the anterior fibers of the masseter muscle.

In its cervical course the facial artery has five major branches. The ascending palatine artery arises near the bifurcation of the lingual-facial trunk. This vessel courses posteriorly, upwards and medially, passing between the styloglossus and stylopharyngeus muscles which it supplies. The vessel terminates on the lateral pharyngeal wall at the level of the palatine tonsil. The submandibular artery is an important vessel which arises from the facial artery when it is in contact with the medial pterygoid muscle; it is the main supply of the submandibular gland. Numerous small muscular arteries supply the medial pterygoid and masseter muscles near their insertion in the area of the angle of the mandible. A small submental branch runs along the inferior border of the mandible; it distributes mainly to the anterior digastric and platysma muscles. As the facial artery 


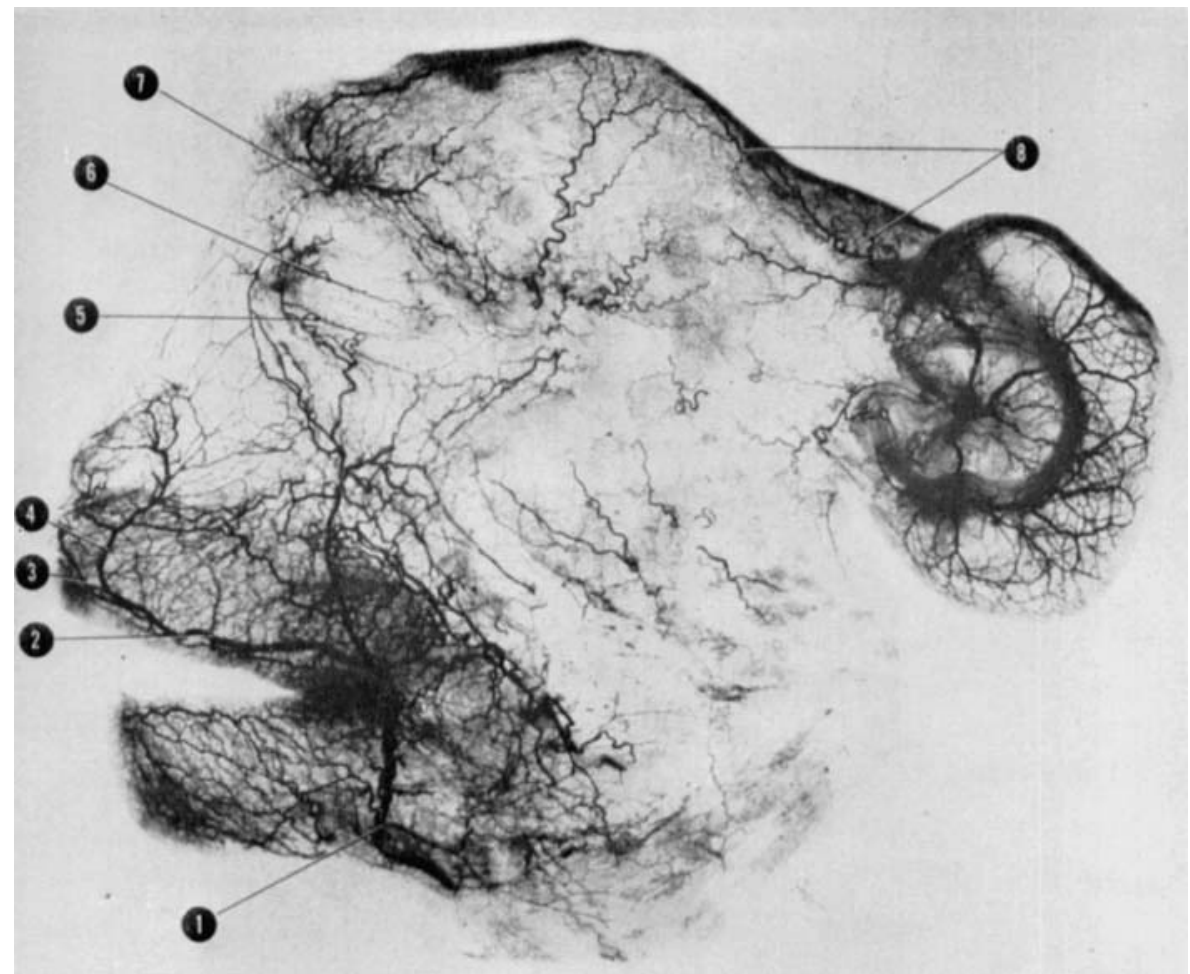

Fig. 5 General distribution of the arterial vessels of the face and part of the scalp. Facial artery (1); superior labial (2); septal branch (3); lateral nasal branch (4); inferior palpebral branch (5); superior palpebral branch (6); supraorbital branch (7); parietal and frontal branches ( 8 ). (Teichmann's paste injection, cleared preparation.)

crosses the inferior border of the mandible, a mylohyoid branch arises from it to pass onto the lateral surface of the mylohyoid muscle. The vessel then continues forward, parallel to the base of the mandible, and supplies the anterior digastric muscles (fig. 6).

The facial artery, as it passes in front of the insertion of the masseter muscle, is anterior to the facial vein. It continues almost vertically upward to the area of the infraorbital foramen where it gives off its terminal branches (fig. 5). On the side of the face it is deep to the buccal pouch and platysma muscle, adjacent to the base of the mandible. The vessel then traverses the muscular mass about the corner of the mouth. Above the corner of the mouth, the facial artery is more superficial, being covered only by the zygomaticoorbital muscle complex. On the side of the face and close to the insertion of the masseter muscle two main buccal pouch branches pass posteriorly, spreading out on the medial and lateral walls of the buccal pouch, where they form an intricate vascular network. The largest branch of the facial artery, the superior labial branch, arises about $1 \mathrm{~cm}$ behind and slightly above the angle of the mouth. It passes horizontally through the upper lip very close to its free border. It then courses upward to the area beneath the ala of the nose. At times this artery appears to be the continuation of the facial, for, above its origin, the facial artery is small. In cleared specimens it can be seen that this branch is the principal supply of the very rich arterial network of the upper lip. The superior labial artery has two principal branches, the lateral nasal branch, which passes upward beneath the external naris and around the ala of the nose to supply the lateral surface of the ala, and a septal branch which courses upward, adjacent to the midline, to the nasal 


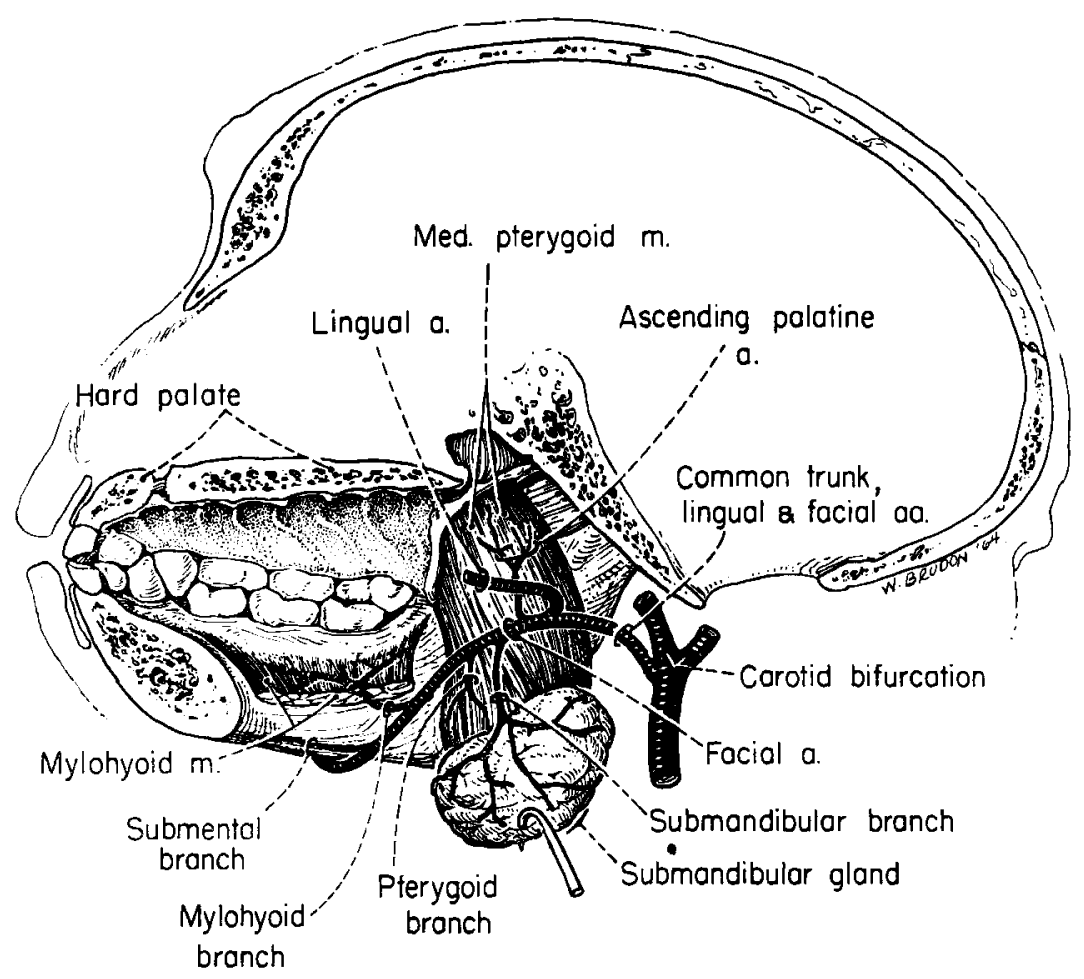

Fig. 6 Schematic drawing of the proximal part of the facial artery.

septum and the skin of the lobe of the nose. These branches anastomose around the external nares (fig. 5).

At the level of the infraorbital foramen the facial artery terminates by sprouting into a variable number of smaller branches. Consistently there are anastomotic branches which join with terminals of the infraorbital artery. Laterally a branch passes along the infraorbital rim to supply the musculature and lateral parts of the lower eyelid. A medial branch, frequently double, passes upward towards the inner canthus of the eye. It passes beneath the orbicularis oculi muscle, supplying it as well as the medial half of the lower eyelid, the lateral side of the bridge of the nose, and the most medial portion of the upper eyelid. At the inner canthus, it anastomoses with very small arteries passing through the orbital septum (fig. 5).

3. The occipital and auricular arteries most frequently arise by a common stem from the external carotid artery as it passes above the posterior digastric muscle. The common trunk passes posteriorly, medial to the posterior digastric muscle and following its fibers. The length of the common trunk is variable; in some cases it reaches the level of the external acoustic meatus before dividing into occipital and auricular branches (figs. 3 and 7 ). The occipital artery, sometimes double, passes lateral to the upper part of the posterior digastric muscle being covered by the splenius capitis and longissimus capitis muscles. It then continues posteriorly and upward along the bone to terminate in branches which supply the muscles attached to the posterior aspect of the skull, and to the overlying scalp. Consistently it gives rise to a branch which perforates the skull by passing through a foreamen approximately $2 \mathrm{~cm}$ posterior to the external acoustic meatus. This is the posterior meningeal artery, the main supply of the posterior lateral portion of the dura mater (fig. 8). 


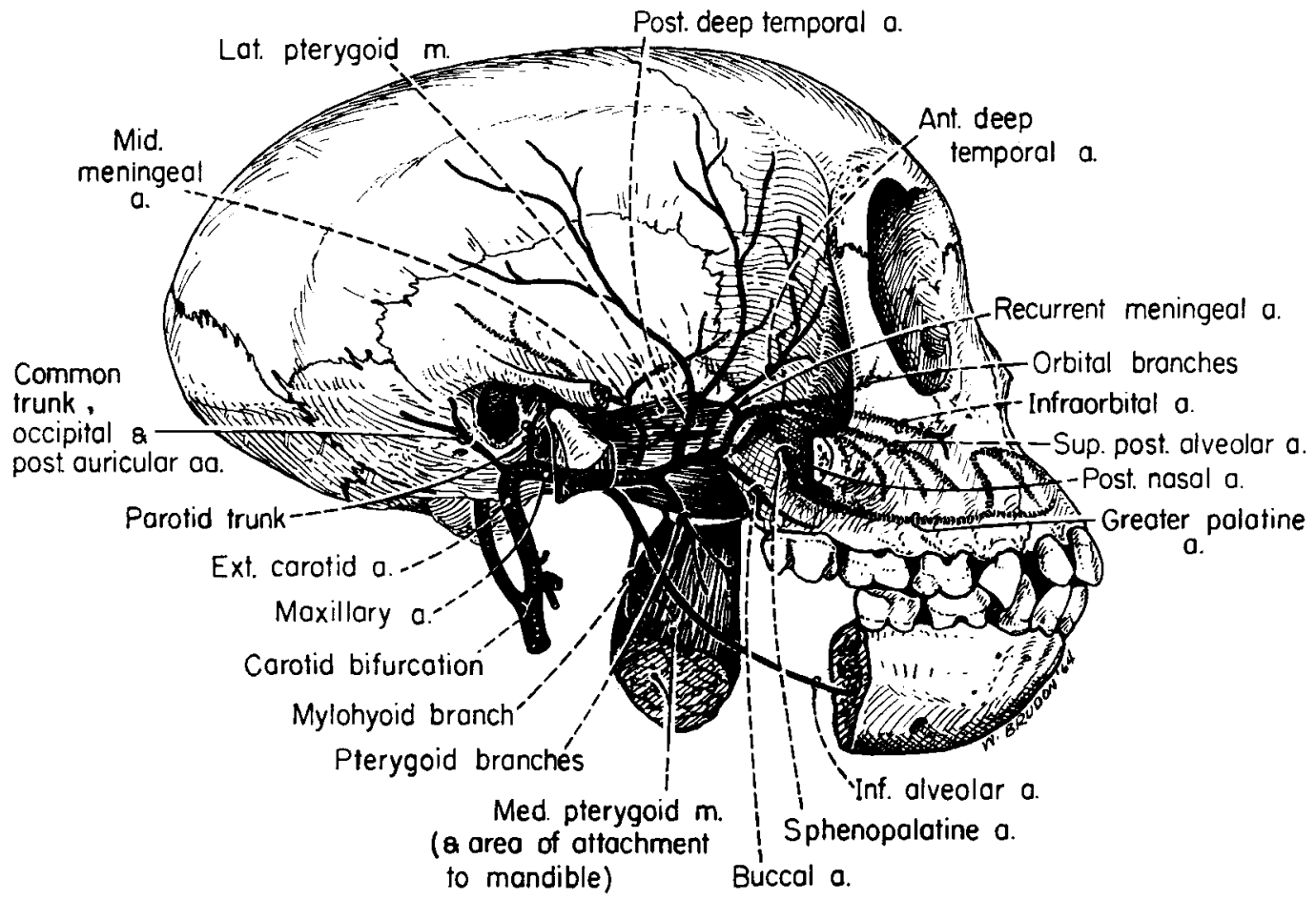

Fig. 7 Schematic drawing showing distribution of the maxillary artery.

The auricular artery is a short trunk which passes upward behind and beneath the lower part of the auricle of the ear where it almost immediately divides into multiple branches. Some of these continue upward along the attachment of the auricle and supply its posterior surface. Others pass over the attachment of the sternomastoid muscle and distribute there. The auricular branches supply adjacent musculature, the lateral and the posterior area of the scalp, and the auricle (fig. 5). The branches to the auricle form rich anastomoses in the form of concentric vascular arches. From these arches, vessels sprout off to form yet smaller vascular networks which are located close to the free edge of the auricle (fig. 5). The artery also gives rise to a small branch which passes through the stylomastoid foramen and accompanies the facial nerve.

4. The ascending pharyngeal artery is a very thin branch arising from the superior medial side of the external carotid artery immediately above the lingual-facial trunk (fig. 3). It passes vertically upward lying on the longus colli muscle. In its upward course the vessel is crossed laterally by the stylopharyngeus and the styloglossus muscles. Near the base of the skull it divides into several terminal branches, one of which passes through the jugular foramen to supply the meninges in the area of the sigmoid sinus. Other branches pass slightly forward and upward to be distributed to the musculature and mucosa of the upper portion of the pharynx. Continuing upward and forward along the base of the skull, the ascending pharyngeal artery supplies the membranous portion of the nasal septum behind the posterior edge of the vomer and behind the hard palate. Small branches from it pass into the soft palate ${ }^{3}$ (fig. 9).

5. The maxillary artery arises about $11 / 2 \mathrm{~cm}$ beneath the external acoustic

3 In the Macacus rhesus, the nasal septum is continued behind the posterior border of the vomer by a triangular-shaped membranous septum which extends backward for about $11 / 2 \mathrm{~cm}$ along the base of the skull. Its inferior attachment is to the soft palate. 


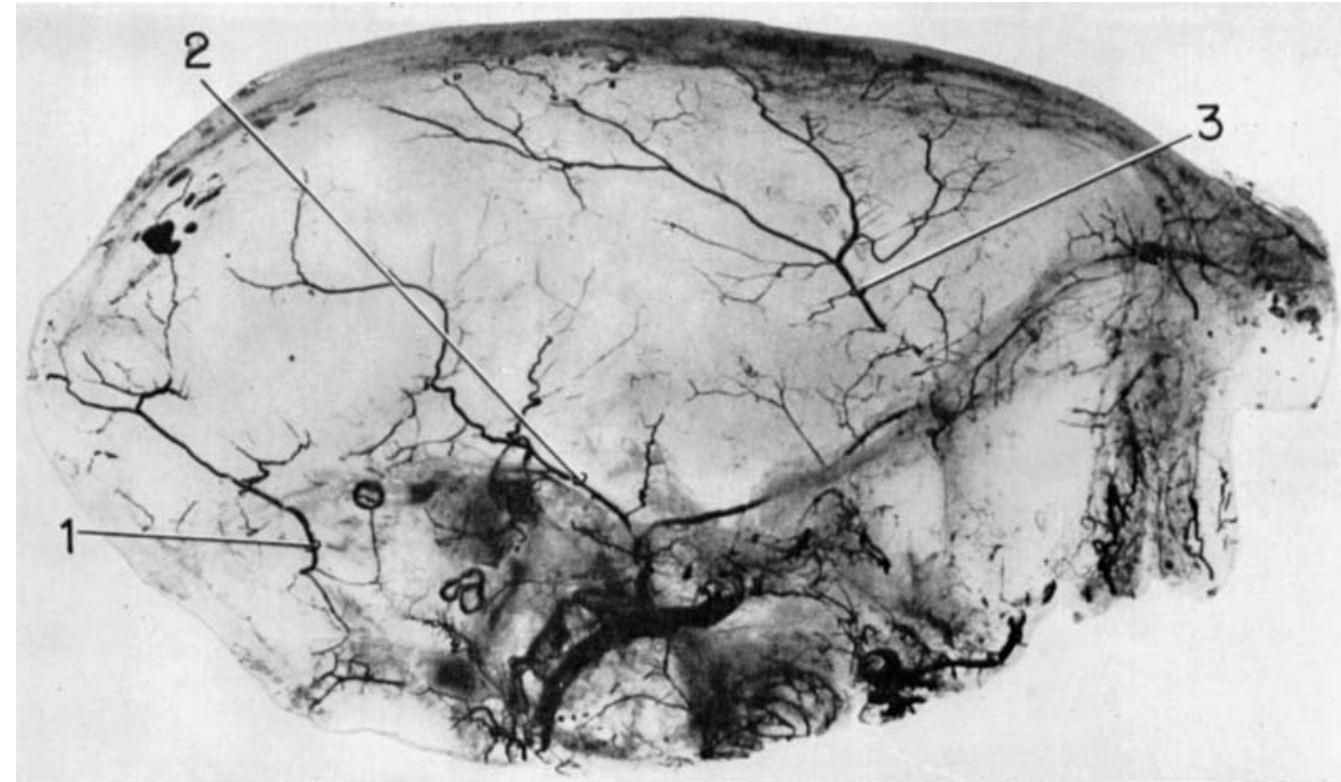

Fig. 8 Disposition of meningeal arteries. Posterior meningeal (1); middle meningeal (2); anterior meningeal ( 3 ). (Teichmann's paste injection, decalcified and cleared preparation.)

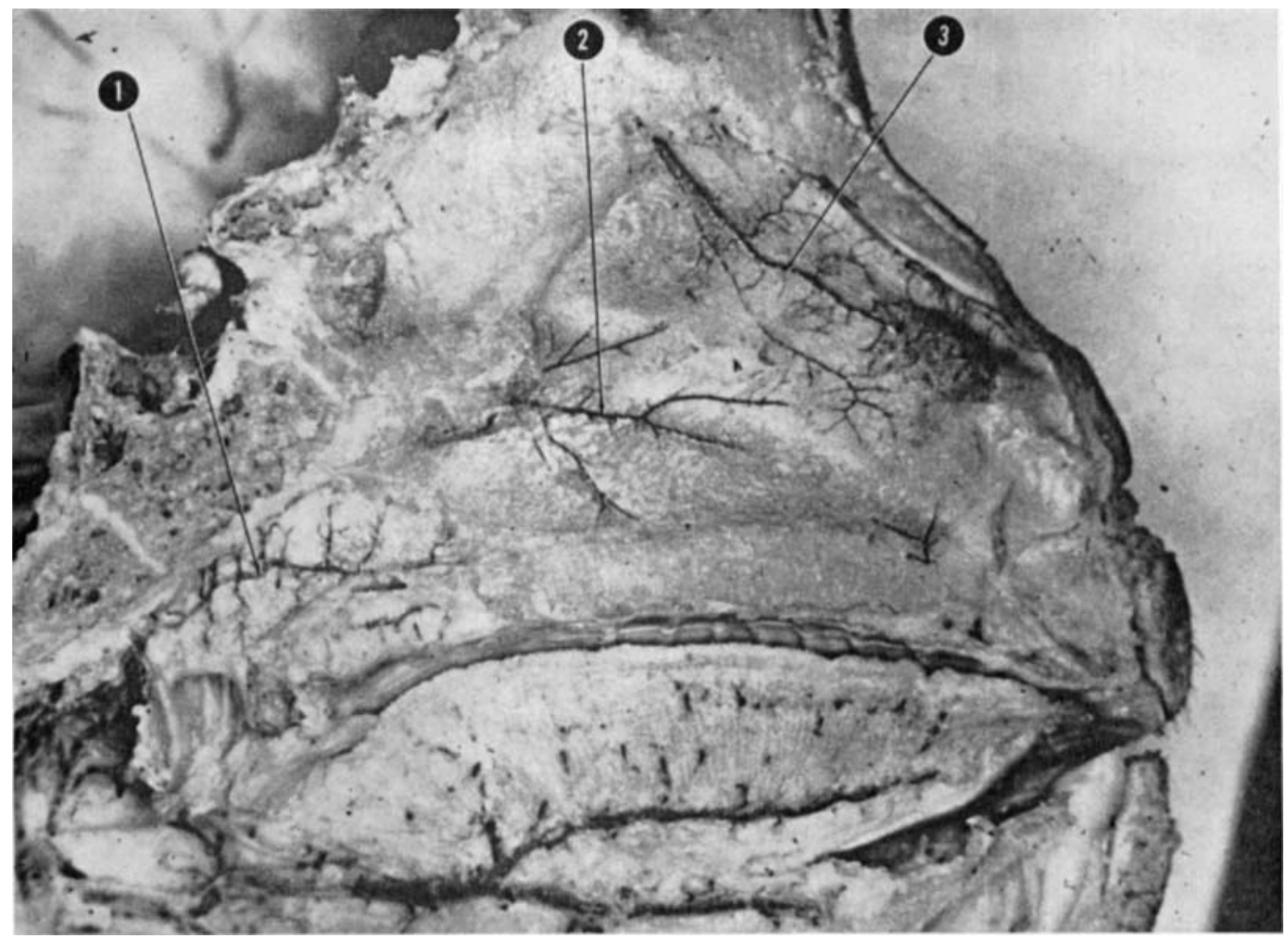

Fig. 9 The arterial supply of the nasal septum. The septal branch of ascending pharyngeal artery (1); nasopalatine branch (2); septal branch of internal nasal artery (3). (Vinyl acetate injection, dissection preparation.) 
meatus and less than $1 \mathrm{~cm}$ behind the ramus of the mandible at the level of the neck of the condyle. As a direct continuation of the external carotid artery it passes horizontally forward medial to the neck of the condyle toward the pterygopalatine fossa. Passing slightly medial and upward throughout this course the artery is in contact with the lower lateral surface of the lateral pterygoid muscle. In the pterygopalatine fossa the vessel terminates by dividing into numerous branches. The main branches of the maxillary artery are 12 in number, several of which arise by common origins (fig. 7).

Very near the point of origin of the maxillary artery, the first branch arises; it is a short parotid trunk which soon divides into six or seven secondary branches. These parotid gland branches spread out in the parotid gland tissue and also supply the adjacent structures (figs. 7, 10 and 11). One of these, a large massetric artery, passes forward along the lateral side of the subcondylar portion of the ramus of the mandible to enter the deep head of the masseter muscle. It supplies most of this muscle and anastomoses along the front edge of the ramus with other branches from the maxillary artery. Near the angle, this artery joins with branches of the facial artery which also supply the inferior part of the masseter muscle (fig. 10). A transverse facial artery likewise is one of these branches which pass horizontally forward, approximately $1 / 2 \mathrm{~cm}$ beneath the zygomatic arch. It joins branches of the facial artery at the lateral inferior margin of the orbit. A very small ascending branch, the zygomaticoorbital artery,

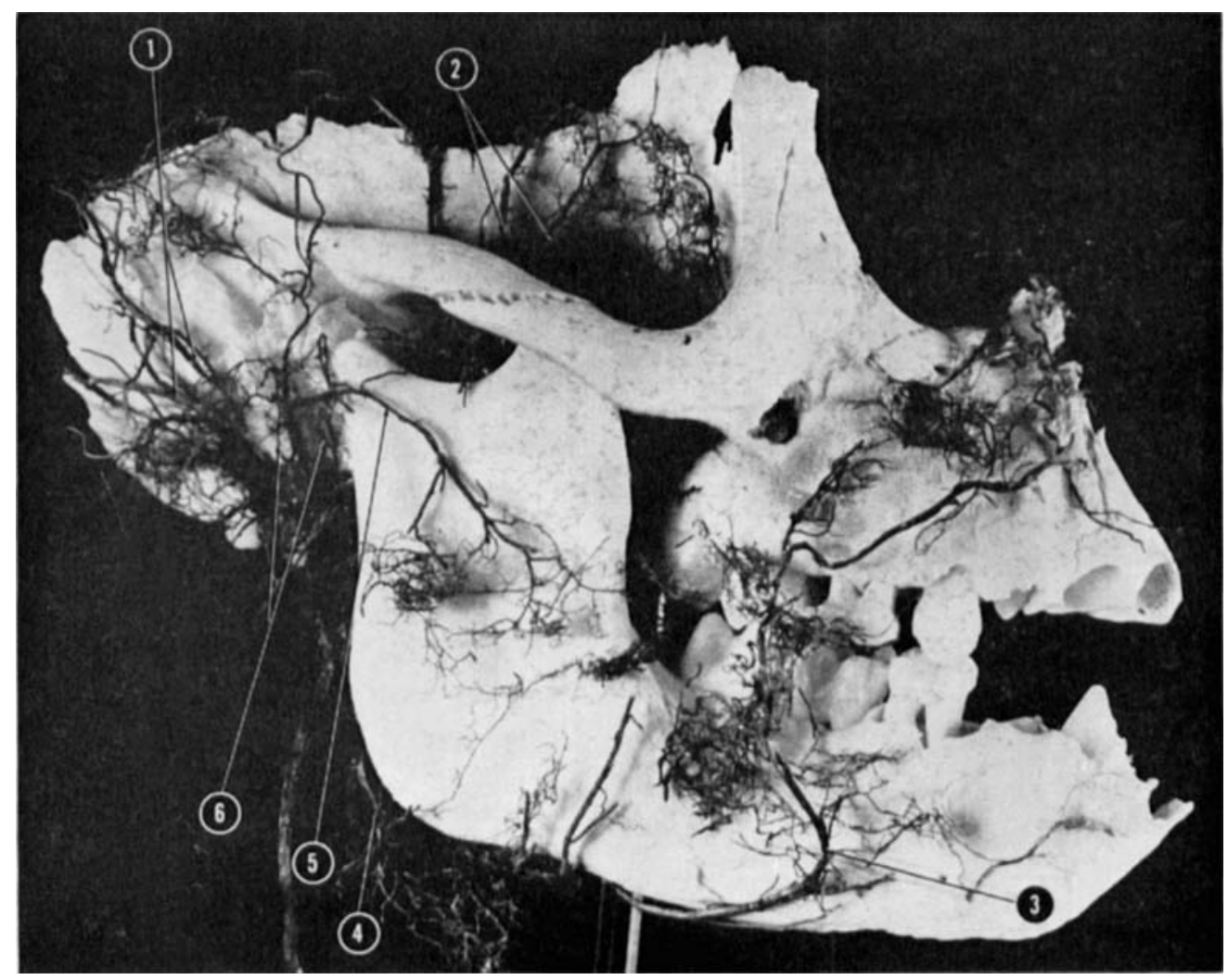

Fig. 10 The main arterial vessels of face, temporal fossa and occipital regions. Occipital and posterior auricular arteries (1); posterior deep temporal artery (2); facial artery (3); submandibular branches (4); masseteric branch (5) and capsular arteries (6). (Vinyl acetate injection, corrosion preparation.) 
courses obliquqely forward to anastomose with the arteries about the orbit. It supplies the skin on the side of the calvarium, and anastomoses at the side of the orbit with lateral branches from the facial as well as supraorbital branches from the ophthalmic artery (fig. 5).

Several small temporomandibular capsular branches arise from the maxillary artery as the vessel passes adjacent to the medial side of the condylar neck. These ascending branches have a very short course, and pass into the medial aspect of the temporomandibular capsule and adjacent tissue. Additionally, articular branches arise from the posterior deep temporal artery near its origin, and from the parotid branches (fig. 11).
The tympanic and middle meningeal arteries arise from a common trunk near the beginning of the maxillary artery, medial to the condylar neck (fig. 11). The trunk passes around the inferior border of the lateral pterygoid muscle to run medially inward toward the petrotympanic fissure. Near the base of the skull the vessel divides into its two named branches (figs. 7 and 8 ). The tympanic artery is very small and passes posteriorly into the petrotympanic fissure towards the middle ear. The meningeal artery passes through the lateral end of the foramen ovale to enter the middle cranial fossa. It grooves the inner table of bone at the base of the middle cranial fossa immediately above the roof of the glenoid cavity. Here it divides into

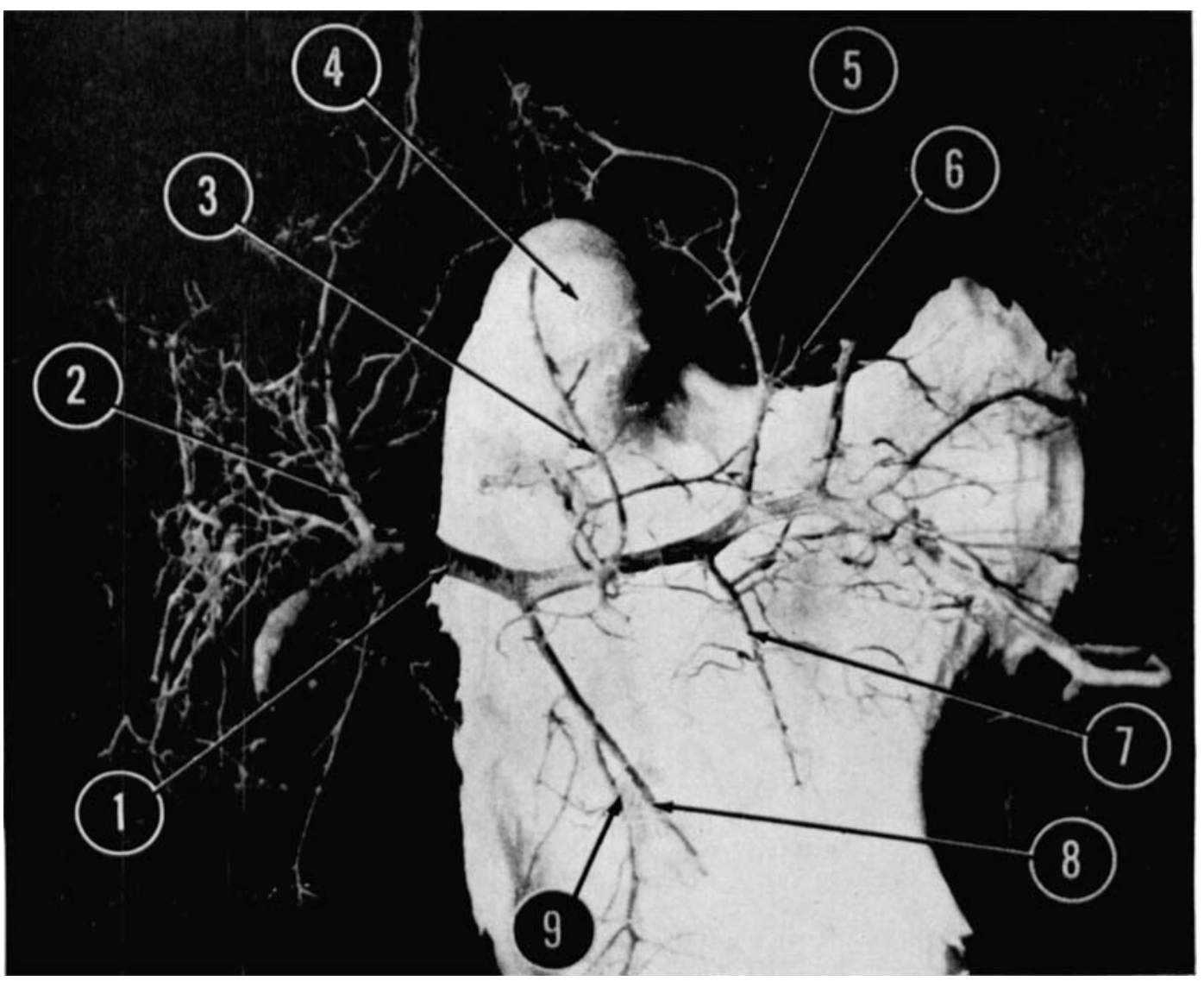

Fig. 11 Vessels in relation to the temporomandibular area. Maxillary artery (1); parotid trunk (2); tympanic-middle meningeal trunk (3); condyle (4); posterior deep temporal artery (5); masseteric branch (6); buccal branch (7); inferior alveolar artery (8); and mylohyoid branch (9). (Vinyl acetate injection; corrosion preparation.) 
two main branches which run anteriorly and posteriorly. The anterior branch passes on the inner aspect of the squamous portion of the temporal bone towards the tip of the lesser wing of the sphenoid bone where it anastomoses with the meningeal branch of the ophthalmic artery. The posterior branch is much smaller and runs over the petrosquamous suture to anastomose with meningeal vessels of the posterior auricular and occipital arteries. In general, the meningeal artery is quite small and in half of the cases most of the medial side of the cranial vault is supplied by a meningeal branch of the ophthalmic artery and by meningeal branches of the occipital and posterior auricular arteries (fig. 8). The middle meningeal artery also has anastomotic connections with its fellow of the opposite side by means of short transverse communications which pass across the top of the skull above the superior sagittal sinus.

A posterior deep temporal artery ascends vertically from its origin in front of the capsule of the temporomandibular joint, passes over the lateral pterygoid muscle which it supplies, and continues upwards to supply the deeper fibers of the temporalis muscle (fig. 18). Here it divides into two or three secondary branches which spread out in a fan-shape manner towards the origin of the temporalis muscle (figs. 7 and 10).

Near the origin of the posterior deep temporal artery, small masseteric and capsular arteries arise which pass downward and posteriorly to their area of supply. The masseteric branch passes through the mandibular notch to supply the upper deep portion of the masseter muscle. It is a much smaller vessel than is the masseteric artery which arises with the parotid branches and is a minor arterial supply of the masseter muscle. The capsular branch, often multiple, fans out as it passes backward to supply the anterior part of the capsule of the temporomandibular joint (figs. 11 and 12).

The inferior alveolar artery arises medial to the neck of the condyle from the lower surface of the maxillary artery. It passes obliquely downward and forward close to the medial pterygoid muscle and the interpterygoid fascia. Before entering the mandibular canal, the inferior alveolar artery usually gives rise to a small mylohyoid branch which distributes to the posterior part of the mylohyoid muscle. Within the mandible, the inferior alveolar artery supplies the dental pulps, periodontal membranes, interdental and interradicular septa, base of the mandible and the area of the angle of the mandible (figs. 7, 11, 12 and 13). A mental artery emerges through the mental foramen and supplies the soft tissue of that area.

Pterygoid arteries supply both the medial and lateral pterygoid muscles. The area of origin of the medial pterygoid muscle receives its blood supply from arteries arising from the tympanic-middle meningeal trunk. These vessels distribute mainly to the area of the pterygoid fossa. The middle portion and mandibular insertion of the medial pterygoid muscle is supplied by branches arising from the inferior alveolar artery, and by small branches arising directly from the maxillary artery. The lateral pterygoid muscle receives small arteries which come directly from the maxillary artery; additionally, the posterior deep temporal artery sends small branches to it.

The buccal artery, accompanied by the buccal nerve, passes downward through the anterior portion of the temporalis muscle to reach the posterior portion of the buccinator muscle to which it distributes. The ascending and lateral branches of the anterior deep temporal arteries also supply the buccinator muscle by small branches which end in the upper posterior portion of the muscle. The main portion of the buccinator is supplied by branches of the facial artery. Anastomosis between all of these vessels occurs within the muscle (figs. 15 and 11).

Three or four anterior deep temporal arteries arise from the maxillary just before it passes into the pterygopalatine fossa (fig. 7). Some ascend into the most anterior fibers of the temporalis muscle while others descend into the fibers which attach to the temporalis crest of the ramus of the mandible.

A few orbital branches arise from the maxillary artery at the pterygopalatine fossa, and pass through the inferior or- 


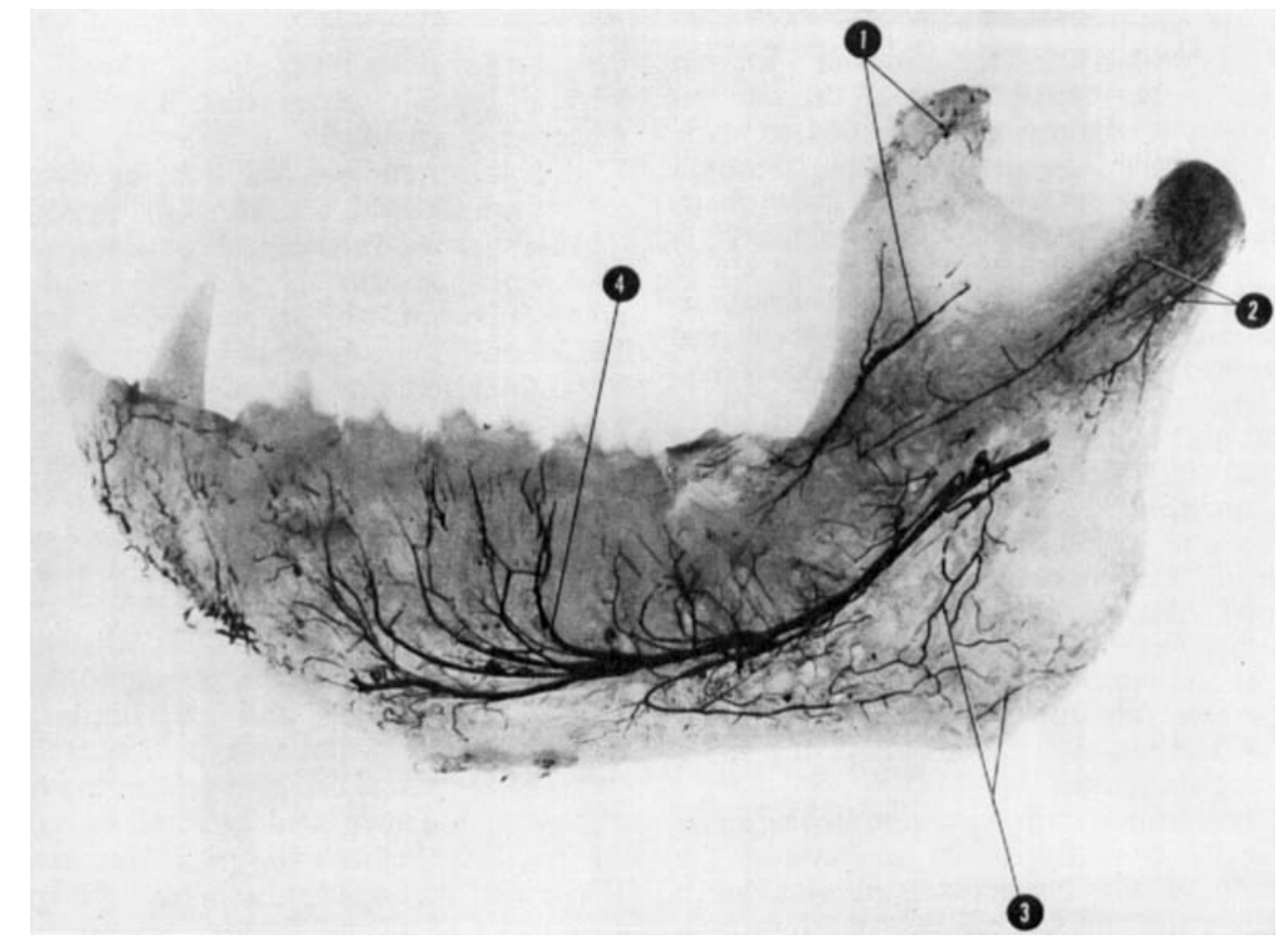

Fig. 12 Differential vascular supply of a mandible with permanent dentition. Arteries of the coronoid process (1) coming from the temporalis muscle. The arteries of the condylar process (2) arise from those of the capsule of the temporomandibular joint and lateral pterygoid muscle. Vessels of the angle region (3) arising from the inferior alveolar artery and from the vessels supplying the muscles attached to it. Branching arrangement of the alveolar dental arteries (4). (Teichmann's paste injection, decalcification and cleared preparation.)

bital fissure to supply the tissues at the apex of the orbit (fig. 14).

The recurrent meningeal artery is extremely small and follows the maxillary nerve, passing posteriorly into the middle cranial fossa where it supplies the area of the trigeminal ganglion (fig. 7).

The posterior superior alveolar artery arises from the maxillary artery at the pterygopalatine fossa. It passes forward for a very short distance along the floor of the orbit, anterior and medial to the inferior orbital fissure, where it enters a small foramen near the anterior end of the fissure (fig. 14). It continues forward in the maxilla above and lateral to the maxillary sinus. Throughout its course alveolar-dental branches are given off which supply the teeth and supporting tissues as far forward as the cuspid tooth. Each alveolar-dental artery divides into secondary branches which supply the den- tal pulps, the periodontal membranes, and the interradicular and interdental septa (fig. 14). The infraorbital branches arise either from the posterior superior alveolar artery or from the sphenopalatine artery. They are small branches which pass forward along the infraorbital nerve by spiraling around and paralleling the nerve throughout its course (fig. 14). Emerging at the infraorbital foramen, these vessels terminate by distributing in the infraorbital area and anastomosing with branches of the facial artery.

The sphenopalatine artery appears to be a direct continuation of the maxillary artery. It passes through the sphenopalatine foramen and, after a short course, gives rise to posterior nasal and descending palatine arteries (fig. 15).

The posterior nasal arteries supply almost all of the lateral nasal wall through superior and inferior branches. The supe- 


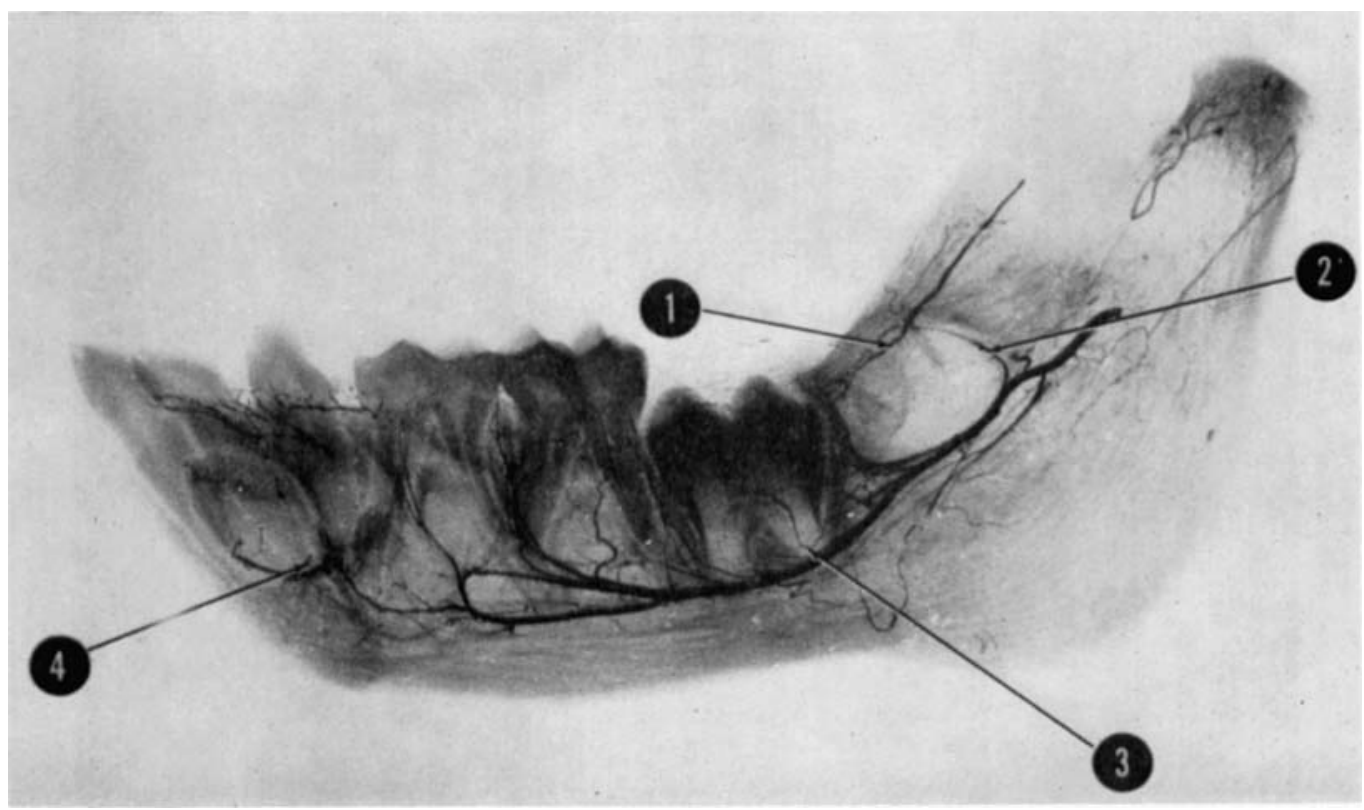

Fig. 13 Arrangement of the vessels in a mandible with mixed dentition. Vascular supply to the second molar tooth bud has two sources: from the vascular system of the temporalis muscle (1) and from the inferior alveolar artery (2); a single vessel from the inferior alveolar artery is supplying the pulp tissue of the developing first molar (3). The inferior alveolar artery ends at the level of the canine tooth (4). (Schlessinger injection media; arteriograph preparation.)

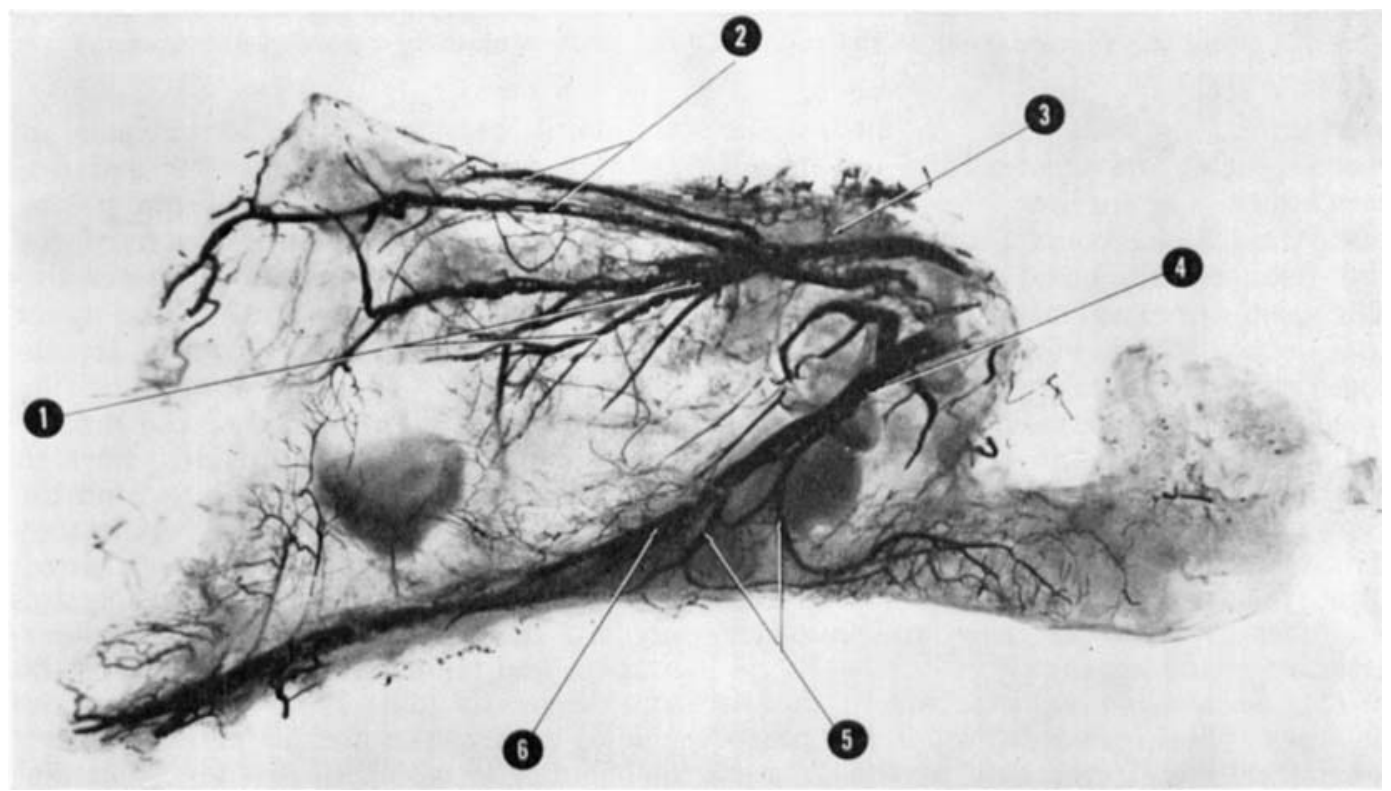

Fig. 14 Distribution of arterial vessels in the maxilla. Posterior alveolar artery (1); infraorbital arteries (2); orbital branches ( 3 ); descending palatine artery (4); lesser palatine arteries (5) and greater palatine artery (6). (Teichmann's paste injection; decalcified and cleared preparation.) 


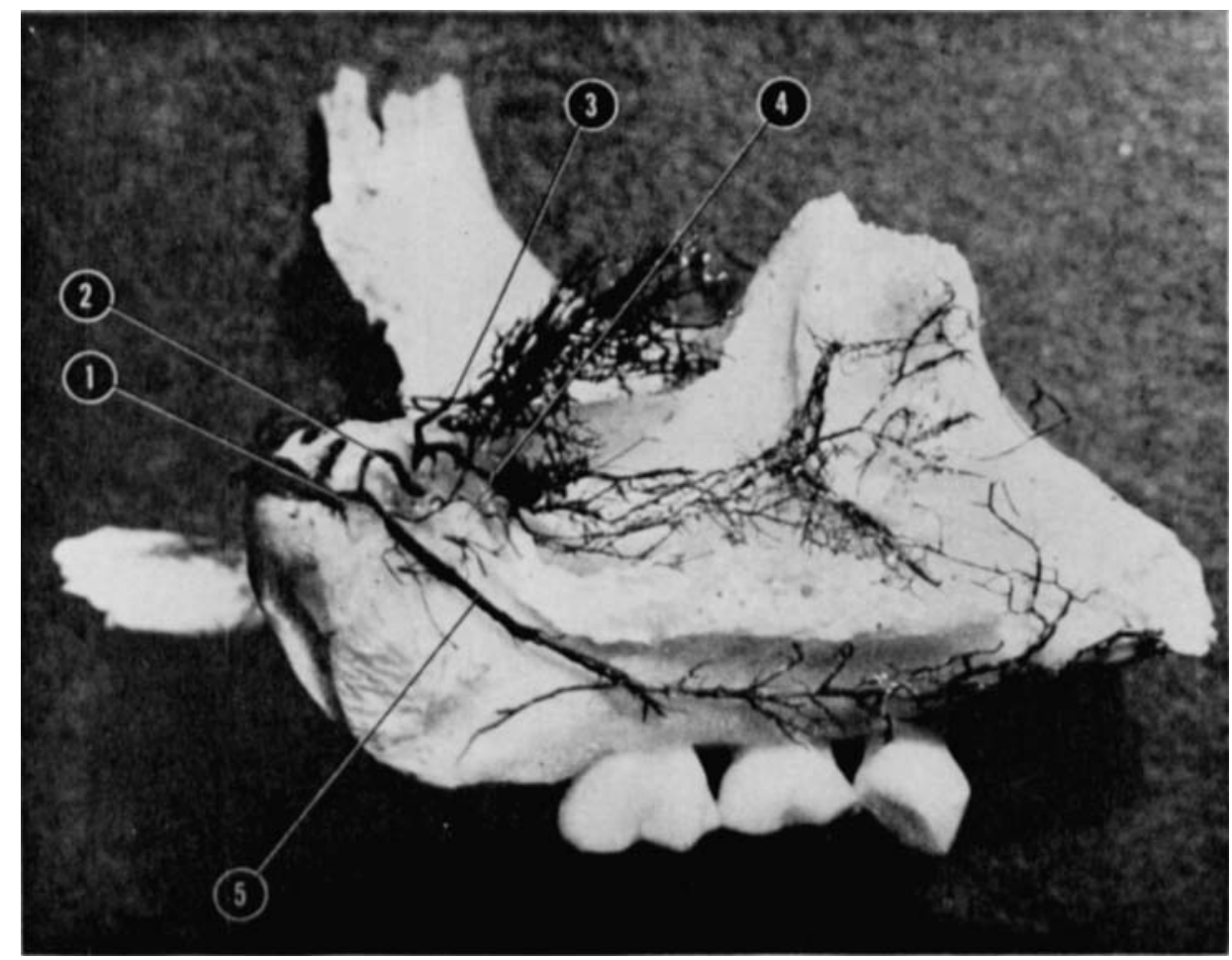

Fig. 15 The sphenopalatine artery (1) branching into the posterior nasal artery (2) with its superior nasal branch (3) and inferior nasal branch (4) and the descending palatine artery (5) spreading out on the palate. (Vinyl acetate injection; corrosion preparation.)

rior branch is distributed to the middle nasal concha and meatus, and the maxillary sinus. The inferior nasal branch supplies the inferior concha and meatus, and the floor of the nasal cavity (fig. 15). The posterior nasal artery also gives rise to a branch which supplies the roof of the nasal cavity, and to a nasopalatine artery which passes to the nasal septum and runs obliquely forward and downward toward the incisive canal through which it passes. Here it anastomoses with the anterior palatine artery (fig. 9). On the nasal septum, the vessel also anastomoses with branches of the posterior and anterior arteries of the septum.

The descending palatine artery passes downward and forward through the pterygopalatine canal emerging at the greater palatine foramen (figs. 14 and 15). As it passes through the pterygopalatine canal, it gives rise to one or two small posterior collateral branches, the lesser palatine arteries (fig. 14). The greater palatine artery is the main supply of the palate, and it is the direct continuation of the descending palatine trunk. It passes forward following the curvature of the upper arch, medial to the teeth, towards the incisive foramen (fig. 16). Lateral to the incisive foramen, branches of the greater palatine artery pass upward through small foramina in the maxilla, behind the anterior teeth. As small thin vessels they surround the apex of the upper central and lateral incisors. These branches supply the dental pulp, periodontal membranes, and supporting bone tissue of the anterior teeth (fig. 17). Throughout its palatal course, the greater palatine artery distributes to adjacent tissue by medial and lateral branches. The medial branches pass toward the midline to anastomose with vessels of the opposite side. Lateral 


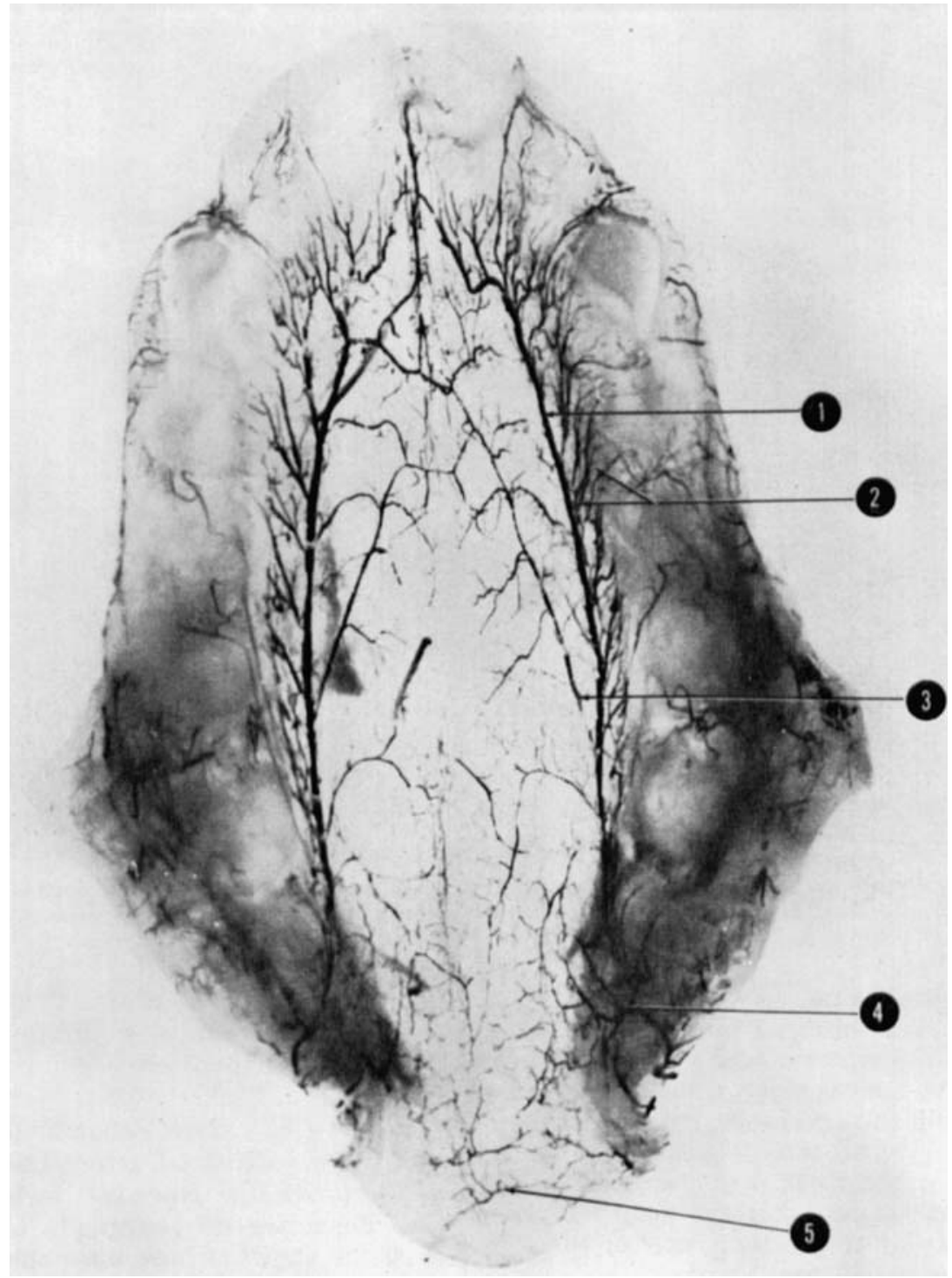

Fig. 16 General distribution of greater palatine artery. Short vessels from the greater palatine artery (1) supply the gingiva and alveolar mucosa (2); palatal vascular arches anastomosing with those of the opposing side (3); lesser palatine artery (4); and arterial plexus in soft palate( 5 ). (Teichmann's paste injection; decalcified and cleared preparation.)

branches are much thinner and supply the alveolar mucosa, gingiva, and alveolar bone (fig. 16).

The lesser palatine arteries distribute mainly to the soft palate. Usually one or two arteries are present, and they anastomose with vessels from the opposite side near the midline of the soft palate (figs. 14 and 16).
Internal carotid artery. From its point of origin, the internal carotid artery passes toward the base of the skull arching slightly forward and medialward (fig. 18).

It is posterior to the external carotid artery which it parallels for $1 \mathrm{~cm}$. The artery is compressed between the posterior digastric and the longus colli muscles; the sympathetic trunk is closely bound to its 


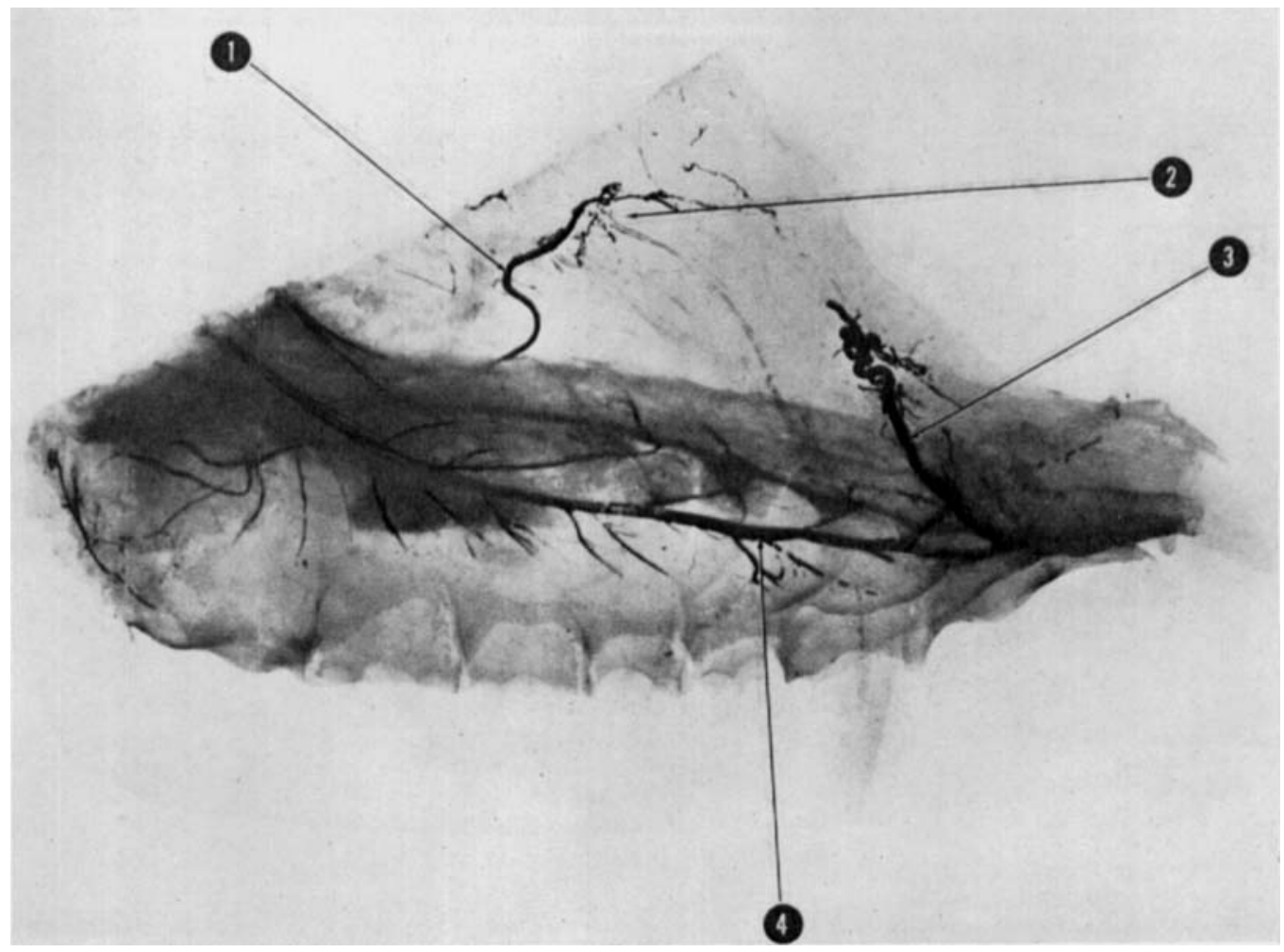

Fig. 17 Profile view of greater palatine artery. Posterior alveolar artery (1); apex of the canine tooth (2); ascending terminal branch of greater palatine artery (3); greater palatine artery (4). (Teichmann's paste injection; decalcified and cleared preparation.)

medial side. The ascending pharyngeal artery passes anterior and medial to it with the vagus nerve and internal jugular vein to its lateral side. Close to the base of the skull the accessory, hypoglassal and glossopharyngeal nerves pass lateral to it.

In the carotid canal of the base of the skull, the internal carotid artery is first perpendicular to the long axis of the petrous portion of the temporal bone and then runs parallel to it. After leaving the carotid canal, the vessel passes through the cavernous sinus where it traces a sigmoid course turning upward at the anterolateral angle of the optic chiasm. The course, distribution, and branches of the internal carotid artery have been adequately described by Weinstein and Hedges ('62) and by Theile ('52).

\section{DISCUSSION}

The general arterial plan of the head and neck of the Macaque follows the pat- tern found in the human. However, some of these vessels have a different arrangement and therefore deserve special comment.

Theile ('52) claims that in the Siminia innus the sublingual artery passes as far as the lower lip. However, in his publication there are no comments nor graphic evidence showing how these arteries were distributed in the area of the mandibular symphysis and lower lip. Our work has confirmed these findings and has explained the distribution of the vessel in these two areas - in the mandible the artery supplies the bone about the symphysis, the dental pulps of the four lower incisors and their supporting tissues, the alveolar bone and the periodontal membrane. This vascular arrangement is similar to that found in the human mandible (Castelli, '63). In the lower lip the artery passes upwards and bifurcates into two 


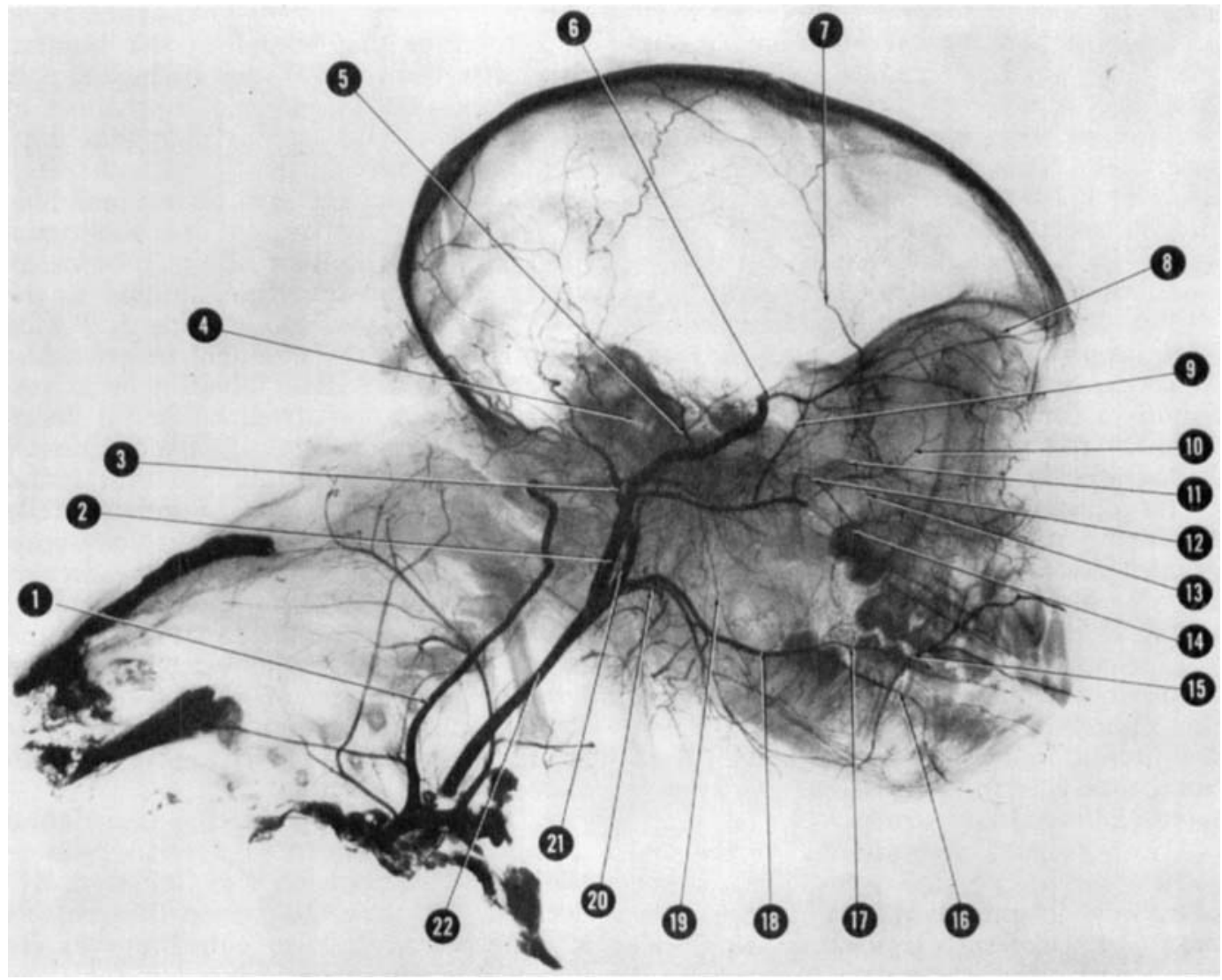

Fig. 18 Arteriograph of head and neck. Principal arteries have been numbered. (Formalin embalmed specimen injected with Schlessinger radioopaque media.)

1. Vertebral artery

2. Internal carotid artery

3. Common trunk for occipital and posterior auricular arteries

4. External auditory meatus

5. Middle meningeal artery

6. Ophthalmic artery

7. Anterior meningeal artery

8. Supraorbital artery

9. Posterior deep temporal artery

10. Anterior deep temporal artery

11. Posterior superior alveolar artery
12. Sphenopalatine artery

13. Posterior nasal artery

14. Descending palatine artery

15. Facial artery

16. Sublingual artery

17. Deep lingual artery

18. Lingual artery

19. Inferior alveolar artery

20. Superior thyroid artery

21. External carotid artery

22. Common carotid artery principal lateral branches close to the free border of the lower lip.

The structure of the nasal septum in the Macaque has revealed an additional nutrient source which is not seen in humans. The nasal septum projects backward as a membranous wall that divides the roof of the nasopharynx into two lateral compartments (Geist, '61). This membranous septum is close to the roof of the pharynx and is supplied by the ascending pharyngeal artery. The vascularization of the septum then is supplied by three main arterial sources - the nasopalatine artery, the septal branch of the sphenopalatine artery, and the septal branch of the ascending pharyngeal artery.

The skin and subcutaneous tissue over the temporal fossa and part of the frontal and parietal areas in the human is sup- 
plied by the superficial temporal artery. In the Macaque, however, this area is supplied by small branches arising from neighboring arteries - posterior deep temporal, posterior auricular, and parotid branches. This arterial disposition may account for the fact that in the Macaque the superficial temporal artery is represented by a very small vessel with limited distribution or is completely absent.

The distribution of the middle meningeal artery in the cranial cavity of the Macaque is somewhat different from that found in the human. Its anterior branch is much reduced in size and distribution. In the Macaque a large meningeal branch of the ophthalmic artery is distributed to the lateral wall of the anterior and middle cranial fossa, the area of supply of the anterior branch of the middle meningeal artery in the human.

Lineback ('61) described the middle meningeal artery as the largest branch of the maxillary artery. We found as did Dyrud ('44) that the posterior deep temporal artery is the largest branch arising from the maxillary artery.

When cleared preparations of the parotid gland are studied a variable number of arterial branches, arising from a common trunk, are seen traversing the glandular tissue. These vessels radiate outward toward the external surface of the gland. The major part of these vessels supply the parenchyma and stroma of the gland. Some of these vessels extend beyond the gland to supply adjacent structures. One artery supplies the masseter muscle and is its main vessel. Others are distributed to a limited area of the face distributing as do the zygomaticoorbital and transverse facial arteries in the human.

The distribution of the vessels supplying the mandible and maxilla have been thoroughly studied in the cleared specimens. In general, the mandible in the Macaque has the same arterial pattern as in the human (Castelli, '63; Cohen, '59); the condyle of the mandible receives its nutrition by means of perforating arteries which come from vessels of the capsule of the temporomandibular joint and from those which supply the lateral pterygoid muscle. Likewise, the origin and the disposition of the vessels which supply the coronoid process and the area of the angle is similar to that found in the human; they arise from those vessels which supply the temporalis muscle and from those of the masseter and medial pterygoid muscles respectively.

Since the incisive area of the mandible is primarily supplied by the sublingual artery, the distribution of the inferior alveolar artery is, therefore, limited to the body of the mandible, for as indicated above, the condyle, coronoid process, and incisive area are all supplied by other vessels. The inferior alveolar arterial distribution and its ascending alveolar-dental branches are quite similar to that found in the human mandible. Fundamentally these vessels branch into thin collaterals to the interalveolar and interradicular septa, to the periodontal membrane and to the pulp of the teeth. It was found that one or two arterial branches passed into the pulp tissue of each dental root. This finding is in agreement with that found in humans (Provenza, '59) and in cats (Castelli, '62).

As far as the supply of the periodontal membrane is concerned several authors (Orban, '53; Schubach and Goldman, '57; Bernick, '60) have suggested that vessels of gingival origin also contribute to the nutrition of the membrane. In fact, the presence of these vessels was not confirmed as an additional vascular source other than those given by the alveolar-dental branches; the only vessels which were found in that area were venous and capillary networks from the periodontium and gingiva at the level of the dental crevice.

In the Macaque the participation of the greater palatine artery in the nutrition of the intermaxillary bone and superior incisors is not like that found in the human. The study of the cleared maxillae in the Macaque shows the absence of the anterior superior alveolar artery. The region of distribution of the anterior superior alveolar artery was supplied by the extension of the greater palatine artery upward into the anterior part of the maxillary bone.

\section{LITERATURE CITED}

Bernick, S. 1960 Blood supply to developing teeth. Anat. Rec., 137: 141-145.

Castelli, W. A. 1962 Vascular structure of dental pulps in cats. J. Dent. Res., 41: 213. 
1963 Vascular architecture of the human adult mandible. J. Dent. Res., 42: 786-792.

Chase, R. E. 1938 The coronary arteries in 266 hearts of rhesus monkey. Am. J. Phys. Anthrop., 23: 299-320.

Chase, R. E., and C. F. DeGaris 1940 On the brachial plexus in macaca rhesus, compared with man. Am. J. Phys. Anthrop., 27: 223-254.

Cohen, L. 1959 Methods of investigating the vascular architecture of the mandible. J. Dent. Res., 38: 920-931.

DeGaris, C. F., and E. M. Glidden 1938 Branches of the aortic arch in 153 rhesus monkeys. Anat. Rec., 70: 251-262.

Dyrud, J. 1944 The external carotid artery of the rhesus monkey (macaca mulatta). Anat. Rec., 90: 17-22.

Eyster, A. B. 1944 The cavernous sinus in a macacus rhesus monkey. Anat. Rec., 90: 37-40.

Geist, D. F. 1961 The anatomy of the rhesus monkey. Edit. by G. C. Hartman and W. L. Strauss, Jr., Hafner Publishing Co., New York. Chapt. IX, 189-209.

Huber, E. 1925 Ein M. Mandibulo-Auricularis Bei Primaten, Nebst Beitragen Zur Kenntnis Der Phylogenese Ohrmuskulatur. Anat. Anz., 60: 11-21.

Kennard, M. A. 1941 Abnormal findings in 264 consecutive autopsies on monkeys. Yale J. Biol. Med., 13: 701-702.

Lineback, P. 1961 The anatomy of the rhesus monkey. Edit. by G. C. Hartman and W. L. Strauss, Jr., Hafner Publishing Co., New York. Chapt. XII, 248-265.

Orban, B. 1953 Oral histology and embryology. Edit. by C. V. Mosby Co., St. Louis, p. 183.
Provenza, D. V. 1959 The blood vascular supply of the dental pulps with emphasis on capillary circulation. Cir. Res., 6: 213-216.

Reiner, L., and F. Rodriguez 1957 An injection mass of maximal radiopacity for postmortem angiography. J. Mount Sinai Hospital, 24: 1139-1145.

Samuel, E. P., and R. Warwick 1955 The origin of the phrenic nerve in the rhesus monkey. J. Comp. Neur., 102: 557-563.

Schubach, P. L., and H. Goldman 1957 A technique of radiographic visualization of the vascular system of the periodontal tissues. $J$. Dent. Res., 36; 245-248.

Schwartz, D. J., and D. F. Huelke 1963 The morphology of the head and neck of the macaca monkey: The muscles of mastication and the mandibular division of the trigeminal nerve. J. Dent. Res., 42: 1222-1233.

Teichmann, L. 1952 Cited by Schwering; Anatomische Trochen-Feucht und Knochenpraparate. Springer Verlag, Berlin, p. 79.

Theile, W. 1952 Die Arteriensystem of Siminia Innus. Archiv Fur Anatomie, Physiologie, und Wissenschaftliche Medicin, 419-428.

Tokarski, S. 1931 Les Variations de L'Artère Maxillaire Interne Chez L'Homme Expliquées par les Variations Chez les Primates. Comp. Rendus, 25: 507-510.

Wagenen, G., and H. R. Catchpole 1956 Physical growth of the rhesus monkey (macaca mulatta). Am. J. Phys. Anthrop., 14: 245-273.

Weinstein, J. D., and T. R. Hedges 1962 Studies of intracranial and orbital vasculature of the rhesus monkey (macaca mulatta). Anat. Rec., 144: $37-42$. 